\title{
Derriçadora portátil na colheita total e seletiva de frutos do cafeeiro
}

\author{
Cristiano Márcio Alves de Souza(1) ${ }^{(1)}$ Daniel Marçal de Queiroz ${ }^{(2)}$ e Leidy Zulys Leyva Rafull(1)
}

\begin{abstract}
(1)Universidade Federal da Grande Dourados, Fac. de Ciências Agrárias, Caixa Postal 533, CEP 79804-970 Dourados, MS. E-mail: csouza@ceud.ufms.br, zulys@ceud.ufms.br (2)Universidade Federal de Viçosa, Dep. de Engenharia Agrícola, CEP 36570-000 Viçosa, MG. E-mail: queiroz@ufv.br
\end{abstract}

Resumo - O objetivo deste trabalho foi avaliar o desempenho de derriçadoras portáteis durante a colheita seletiva e total dos frutos, em dois sistemas de colheita. Foram determinados a carga pendente da planta, a capacidade de derriça, o índice de desfolha, a eficiência de derriça, o índice de frutos verdes no produto, o nível de ruído e o consumo horário e específico de combustível. O sistema de colheita, utilizando-se duas derriçadoras portáteis, simultaneamente na mesma fileira de cafeeiros, apresentou melhor desempenho. A colheita seletiva foi muito influenciada pela porcentagem de frutos maduros e carga pendente do cafeeiro.

Termos para indexação: desempenho, mecanização agrícola, energia, ergonomia.

\section{Portable harvester in the total and selective harvesting of coffee fruits}

\begin{abstract}
The objective of this work was to evaluate the performance of a portable coffee harvester to mountain areas. Two procedures were tested: harvesting all fruits in only one operation, and the selective harvesting. Coffee yield, harvesting capacity, index of leaves taken during harvesting process, harvesting efficiency, noise level and fuel consumption were measured. The harvesting system with two portable harvester presented better performance than with only one machine. Selective harvesting was highly influenced by the percentage of ripen fruits and by coffee yield.
\end{abstract}

Index terms: harvesting capacity, agricultural mechanization, energy, ergonomics.

\section{Introdução}

O Brasil é o maior produtor e exportador de café no mercado internacional. Atualmente, a cafeicultura de montanha abrange 1,5 bilhões de cafeeiros, localizados na Zona da Mata de Minas Gerais, parte do Estado do Espírito Santo e do Estado do Rio de Janeiro e pequenas áreas do sul de Minas, São Paulo e Paraná. Esse número representa aproximadamente $30 \%$ da população cafeeira do Brasil.

A colheita dos frutos do cafeeiro está dividida em seis operações: arruação, derriça, varrição, recolhimento, abanação e transporte. A derriça do fruto do cafeeiro pode ser seletiva ou total, e operações podem ser realizadas de forma manual, semi-mecanizada e mecanizada (Silva et al., 1997). Na colheita seletiva, apenas os frutos maduros são colhidos, enquanto na derriça total, os frutos são apanhados em todos os estádios de maturação. A derriça total é a prática mais usada na colheita de frutos do cafeeiro no Brasil.
Independentemente de qual seja o sistema de colheita utilizado, a derriça é a operação mais complexa. Segundo Bártholo \& Guimarães (1997), quando realizada de forma manual, a derriça representa até $75 \%$ do tempo despendido na colheita. Por esse motivo, nos últimos anos, têm sido introduzidas derriçadoras portáteis, que são máquinas apropriadas para pequenos e médios produtores de café e para regiões de declividade superior a 20\% (Matiello et al., 2002).

Essas máquinas podem ser de acionamento elétrico, pneumático, ou por um motor de combustão interna. O princípio de funcionamento é por vibração e contato, possibilitando, dessa forma, a colheita seletiva e, assim, contornando o problema da desuniformidade de maturação dos frutos do cafeeiro no momento da colheita.

O café plantado em áreas de montanhas, pelas características próprias da região e pela predominância de pequenas propriedades, pode ser favorecido com a introdução das derriçadoras portáteis. 
Além de suprir a escassez de mão-de-obra, observada em lavouras cafeeiras, a adoção desse tipo de máquina pode melhorar a remuneração dos trabalhadores, já que seu uso e sua manutenção exigem maior qualificação técnica.

Ensaios realizados têm demonstrado que as derriçadoras portáteis existentes no mercado podem ter seu desempenho melhorado, em relação à capacidade e eficiência de derriça e menor desfolhamento do cafeeiro (Souza, 2004; Barbosa et al., 2005). Assim, são necessários estudos a fim de torná-las mais viáveis tecnicamente e economicamente e adaptadas à cafeicultura de montanha.

Um dos aspectos do funcionamento desse tipo de maquinário é o nível de ruído produzido por máquinas, quando se pretende aprimorar as condições de trabalho, pois o desempenho do operador melhora, sob condições menos ruidosas e mais confortáveis. Souza et al. (2005) avaliaram os níveis de ruído emitidos por uma derriçadora portátil, e concluiram que os níveis de ruído estavam acima dos limites estabelecidos pela NBR 10152 (ABNT, 1987) e pela NR 15 (CLT) (Brasil, 1998).

A ação das máquinas derriçadoras sobre o cafeeiro ocasiona danos como desfolha, quebra de galhos e descorticamentos. Isto indica que as máquinas que proporcionam baixo índice de desfolhamento devem ser preferidas, pois, além de preservarem a estrutura arbórea da planta, também podem garantir um produto de melhor qualidade, com menor presença de impurezas. Perdas financeiras provenientes de um preparo inadequado no processo de cultivo do café podem variar de 10 a $20 \%$, quanto ao aspecto do produto, e podem chegar a $40 \%$, quanto à classificação da bebida (Filgueiras, 2000).

A fim de oferecer informações aos produtores de café de montanha sobre o uso de derriçadoras portáteis na colheita dos frutos maduros, este trabalho teve como objetivo avaliar o desempenho de derriçadoras portáteis durante a colheita seletiva e total dos frutos, em dois sistemas de colheita e em diferentes condições de lavouras.

\section{Material e Métodos}

Este trabalho foi realizado no Dep. de Engenharia Agrícola da Universidade Federal de Viçosa e na Fazenda Lage, localizada no Município de Viçosa, MG, durante a safra de 2004. As lavouras estavam localiza- das em terreno com relevo acidentado, com declividade entre 17 a 33\%, característico da região da Zona da Mata mineira.

Foram realizados dois experimentos: o primeiro, para avaliar a influência do sistema de colheita sobre o desempenho de derriçadoras portáteis, em uma lavoura de café com 11 anos de plantio, espaçamento de 2,8x0,8 m e cafeeiros com altura de 2,5 m; o segundo experimento, para avaliar a capacidade de seletividade da máquina durante a colheita de frutos maduros, em lavouras com quatro anos, espaçamento de $3 \times 1 \mathrm{~m}$ e de 1,39 m de altura média. Todos os testes foram realizados em cafeeiros da variedade Catuaí.

As derriçadoras portáteis avaliadas são do modelo DK423CB, acionadas por um motor de combustão interna de dois tempos, com potência de $0,88 \mathrm{~kW}$, cilindrada de $23 \mathrm{~cm}^{3}$ e rotação de $11.700 \mathrm{rpm}$. A massa da derriçadora é de 6,7 kg e o movimento dos dedos é vibratório. O sistema de transmissão de potência do motor aos dedos é formado por um cabo de aço e um conjunto de coroa e pinhão.

Os operadores das máquinas trabalharam com esse tipo de equipamento durante duas safras. Além de terem realizado a colheita total dos frutos durante os períodos apropriados, também experimentaram a colheita seletiva dos frutos maduros.

Nos dois experimentos, foram realizados os mesmos testes, e cada teste consistiu em derriçar 32 planta de maneira consecutiva. Foram medidos os volumes de frutos colhidos e de frutos não derriçados, a massa de folhas desprendidas e galhos quebrados dos cafeeiros, o consumo de combustível da máquina, o nível de ruído e o tempo de derriça dos frutos. Os frutos colhidos foram classificados, por estádio de maturação, em verdes, maduros e secos. Foram determinadas a carga pendente da planta, capacidade de derriça, índice de desfolha, eficiência de derriça e consumo horário e específico de combustível.

A carga pendente das plantas, no ato da colheita, foi determinada, somando-se os volumes de frutos derriçados e os não derriçados. A unidade da carga pendente foi expressa em litros de frutos por cafeeiro.

A capacidade de derriça foi determinada pela relação entre o volume de frutos derriçados e o tempo despendido durante o processo:

$\mathrm{C}_{\mathrm{d}}=60\left(\mathrm{v}_{\mathrm{d}} / \mathrm{t}_{\mathrm{d}}\right)$

em que, $C_{d}$ é a capacidade de derriça $\left(\mathrm{L} \mathrm{h}^{-1}\right)$; $\mathrm{v}_{\mathrm{d}}$ é o volume de frutos derriçados (L); $\mathrm{t}_{d}$ é o tempo de derriça (min). 
A eficiência de derriça foi obtida, calculando-se a quantidade de frutos do cafeeiro derriçados pela máquina, em relação à quantidade inicial, conforme a expressão: $\xi_{\mathrm{d}}=100 \mathrm{v}_{\mathrm{d}} /\left(\mathrm{v}_{\mathrm{d}}+\mathrm{v}_{\mathrm{p}}\right)$

em que, $\xi_{\mathrm{d}}$ é a eficiência de derriça (\%); $\mathrm{v}_{\mathrm{p}}$ é o volume dos frutos não derriçados (L).

Os danos provocados pela derriça mecânica foram quantificados pela massa de folhas caídas e de galhos quebrados, durante a derriça, em relação à massa de frutos derriçados:

$\mathrm{D}_{\mathrm{f}}=\mathrm{m}_{\mathrm{f}} / \mathrm{v}_{\mathrm{d}}$

em que, $\mathrm{D}_{\mathrm{f}}$ é o índice de desfolha provocada ao cafeeiro $\left(\mathrm{g} \mathrm{L}^{-1}\right) ; \mathrm{m}_{\mathrm{f}}$ é a massa de folhas e galhos quebrados.

O consumo de combustível foi determinado diretamente no tanque de combustível da derriçadora, por diferença de volumes medidos antes e depois da realização de cada ensaio, utilizando-se uma bureta, com precisão de $1 \mathrm{~mL}$. Depois de medidos o consumo de combustível e o tempo de derriça, determinou-se o consumo horário de combustível, conforme se segue:

$\mathrm{C}_{\mathrm{h}}=60 \mathrm{C} / \mathrm{t}_{\mathrm{d}}$

em que, $\mathrm{C}_{\mathrm{h}}$ é o consumo horário de combustível, $\left(\mathrm{L} \mathrm{h}^{-1}\right)$; C é o consumo de combustível e óleo lubrificante (L).

O consumo específico de combustível foi determinado conforme se segue:

$\mathrm{Ce}=1000 \mathrm{C}_{\mathrm{h}} / \mathrm{C}_{\mathrm{d}}$

em que, $\mathrm{C}_{\mathrm{e}}$ é o consumo horário de combustível, mililitro de mistura (combustível e lubrificante) por litro de frutos derriçados.

O nível de ruído emitido pela derriçadora foi medido a $20 \mathrm{~mm}$ do ouvido do operador, usando um decibelímetro MINIPA, modelo MSL-1350, no circuito de resposta lenta e de equalização "A". Os dados de nível de ruído foram comparados com os limites de conforto definidos pela NBR 10152 (ABNT, 1987), que estabelece os níveis máximos de ruído que proporcionam o mínimo de conforto aos ocupantes de um ambiente, e com os limites definidos na portaria n으 3214, de 8 de junho de 1978, publicada como Norma Regulamentadora NR 15, da Consolidação das Leis do Trabalho.

A fim de avaliar a influência do sistema de colheita sobre o desempenho das máquinas, foram realizados ensaios de campo com duas derriçadoras. No sistema de colheita 1 (SC1), foram usadas duas derriçadoras, uma em cada linha de plantio, onde cada operador era responsável por derriçar os frutos dos dois lados do cafeeiro. No segundo sistema de colheita (SC2), foram usadas duas derriçadoras, operando simultaneamente na mesma linha, e cada operador era encarregado por derriçar os frutos de um lado do cafeeiro.

A fim de avaliar a capacidade de seletividade da máquina durante a colheita de frutos maduros, foi conduzido um experimento usando-se o sistema de colheita com melhor rendimento, determinado no experimento anterior. Os testes foram realizados em duas lavouras de café, denominadas lavoura 1 e lavoura 2, com alturas de aproximadamente 1,35 e 1,43 m, respectivamente.

Durante a colheita seletiva dos frutos do cafeeiro, não foi fixado valor da aceleração das hastes vibradoras da derriçadora, e o controle da aceleração ficou sob a resposabilidade do operador. Recomendou-se que os valores de aceleração fossem menores que os observados na colheita total dos frutos, visando a diminuição de frutos verdes nos derriçados. Na colheita total dos frutos, o operador manteve totalmente pressionado o gatilho de aceleração da derriçadora, enquanto a garra esteve em contato com os galhos. De acordo com Souza et al. (2002), o aumento da energia de vibração causa aumento de frutos verdes no produto colhido. Esses frutos verdes afetam negativamente a classificação da bebida.

Nos experimentos foram retiradas amostras de frutos no produto colhido para se determinar o teor de água, utilizando-se o método de estufa a $105 \pm 2^{\circ} \mathrm{C}$ por 24 horas, com quatro repetições.

Os dados obtidos foram submetidos à análise de variância e de regressão, e os modelos foram selecionados com base no coeficiente de determinação e na significância dos coeficientes de regressão, utilizandose o teste $t$, a $5 \%$ de probabilidade. Na análise da influência do sistema de colheita sobre o desempenho da máquina e da porcentagem de maduros sobre a colheita seletiva, realizou-se o teste $\mathrm{F}$, a 1 e $5 \%$ de probabilidade. Nas análises estatísticas, utilizou-se o programa computacional SAEG, versão 8 (Ribeiro Júnior, 2001).

\section{Resultados e Discussão}

Os teores de água dos frutos no estádio de maturação verde, maduro e seco foram de $68,0 \pm 0,7 ; 66,1 \pm 0,3$ e $42,9 \pm 5,2 \%$ base úmida, respectivamente.

No experimento em que foi avaliada a influência do sistema de colheita e realizada a derriça total dos frutos, não houve diferença significativa entre as porcentagens 
de frutos verdes para os dois sistemas de colheita. A porcentagem média de frutos verdes foi de $29,5 \%$, ou seja, em média as plantas colhidas apresentavam $70,5 \%$ de frutos maduros e secos (Tabela 1).

O nível de ruído de fundo médio determinado no primeiro experimento foi de $49 \mathrm{dBA}$. Os dados de capacidade de derriça, índice de desfolha, consumo horário e específico de combustível enível de ruído foram determinados durante a derriça dos frutos realizada nos dois sistemas de colheita. Quando foi adotado o SC2, houve maior capacidade de derriça e índice de desfolha, e menor consumo específico de combustível do que quando foi usado o SC1 (Tabela 2).

A maior capacidade de derriça pode ser atribuída ao fato de que quando foi usado o SC2, a colheita foi realizada sem necessidade de o operador gastar tempo na passagem para o outro lado da linha de cafeeiros e retornar para continuar a colheita, como acontece com o SC1.

A desfolha foi maior durante o uso do SC2, possivelmente em virtude do efeito da vibração provocada pela ação das duas máquinas derriçando, conjuntamente, cada lado da mesma planta. A desfolha nem sempre é prejudicial ao cafeeiro, pois, embora possa causar aumento de impurezas no material colhido, afetando a qualidade do café, ela também é um indicador da queda de folhas e galhos velhos e doentes, conforme Aristizábal-Torres et al. (2000). Assim, pode-se dizer que a ação da máquina pode facilitar a poda sanitária da planta.

Na análise do nível de ruído e do consumo horário de combustível, não houve diferença significativa de seus valores, quando foram usados os dois sistemas de colheita (Tabela 2).

Tabela 1. Frutos verdes, maduros e secos presentes na planta $(\%)$ e no repasse (\%), para a colheita realizada por dois sistemas de colheita ${ }^{(1)}$.

\begin{tabular}{|c|c|c|c|c|c|c|}
\hline \multirow{2}{*}{$\begin{array}{l}\text { Sistema } \\
\text { de } \\
\text { colheita }^{(2)}\end{array}$} & \multicolumn{3}{|c|}{$\begin{array}{c}\text { Frutos presentes } \\
\text { na planta }\end{array}$} & \multicolumn{3}{|c|}{$\begin{array}{c}\text { Frutos } \\
\text { no repasse }\end{array}$} \\
\hline & $\overline{\text { Verdes }}$ & Maduros & Secos & Verdes & Maduros & Secos \\
\hline$\overline{\mathrm{SC} 1}$ & $30,0 \mathrm{a}$ & $30,8 \mathrm{a}$ & $39,2 \mathrm{a}$ & $49,3 a$ & $30,4 a$ & $20,3 a$ \\
\hline $\mathrm{SC} 2$ & $29,1 \mathrm{a}$ & $39,2 b$ & $31,8 b$ & $52,0 \mathrm{a}$ & $33,2 \mathrm{a}$ & $14,8 \mathrm{a}$ \\
\hline
\end{tabular}

(1)Médias seguidas de mesma letra, nas colunas, não diferem entre si pelo teste $\mathrm{F}$, a $5 \%$ de probabilidade. ${ }^{(2)} \mathrm{SC} 1$ : uma derriçadora em cada linha de plantio; SC2: duas derriçadoras, simultaneamente, na mesma linha de plantio.
O menor consumo específico de combustível observado no SC2 está associado à diferença verificada entre os valores de capacidades de derriça dos sistemas de colheita, que apresentou maior valor para o SC2. A diferença entre os valores de consumo específico de combustível é inversamente proporcional à diferença entre as capacidades de derriça.

O sistema de colheita não influenciou a eficiência de derriça dos frutos do cafeeiro, apresentando média de 97,9\% (Tabela 2). Esse valor é superior ao obtido por Oliveros-Tascón et al. (2005), de 82,5\%. Não houve diferença significativa entre as porcentagens de frutos verdes, maduros e secos no repasse para os dois sistemas de colheita (Tabela 1). Houve maior porcentagem de frutos verdes no repasse, representando aproximadamente $50,6 \%$ do total de frutos não derriçados da planta.

A capacidade de derriça da máquina aumentou com o incremento da carga pendente do cafeeiro, independentemente do sistema de colheita (Figura 1). O SC2 apresentou os maiores valores de capacidade de derriça, independentemente da carga pendente do cafeeiro.Verificou-se que, em ambos os sistemas de colheita, houve aumento da capacidade de derriça com o aumento da porcentagem de frutos maduros e secos (Figura 2). Esse fato está associado à maior facilidade de desprendimento dos frutos maduros e secos, conforme Souza (2004).

Ao se considerar que a capacidade de derriça foi 39\% superior e que o consumo específico de combustível foi $41,4 \%$ inferior ao SC1, pode-se afirmar que o SC2 apresentou melhor desempenho operacional na derriça. Dessa forma, optou-se por realizar o experimento a fim de estudar o efeito da porcentagem de frutos maduros e secos sobre o desempenho das derriçadoras, com o SC2.

Tabela 2. Capacidade de derriça (litros de frutos por hora), índice de desfolha (gramas de folhas por litro de frutos), eficiência de derriça (\%), consumo horário $\left(\mathrm{L} \mathrm{h}^{-1}\right)$ e específico de combustível ( $\mathrm{mL} \mathrm{L}^{-1}$ de frutos) e nível de ruído (dBA) de acordo com o sistema de colheita ${ }^{(1)}$.

\begin{tabular}{lcccccc}
\hline $\begin{array}{l}\text { Sistema de } \\
\text { colheita }^{(2)}\end{array}$ & $\begin{array}{c}\text { Capacidade de } \\
\text { derriça }\end{array}$ & $\begin{array}{c}\text { Índice de } \\
\text { desfolha }\end{array}$ & $\begin{array}{c}\text { Eficiência } \\
\text { de derriça }\end{array}$ & $\begin{array}{c}\text { Consumo Consumo } \\
\text { horário específico }\end{array}$ & $\begin{array}{c}\text { Nível de } \\
\text { ruído }\end{array}$ \\
\hline SC1 & $187,8 \mathrm{a}$ & $132,4 \mathrm{a}$ & $98,0 \mathrm{a}$ & $0,87 \mathrm{a}$ & $4,63 \mathrm{a}$ & $112,9 \mathrm{a}$ \\
SC2 & $310,2 \mathrm{~b}$ & $154,3 \mathrm{~b}$ & $97,8 \mathrm{a}$ & $0,84 \mathrm{a}$ & $2,71 \mathrm{~b}$ & $111,8 \mathrm{a}$ \\
\hline
\end{tabular}

(1)Médias seguidas de mesma letra, nas colunas, não diferem entre si pelo teste $\mathrm{F}$, a $5 \%$ de probabilidade. ${ }^{(2)} \mathrm{SC} 1$ : uma derriçadora em cada linha de plantio; SC2: duas derriçadoras, simultaneamente, na mesma linha de plantio. 
Embora o SC2 tenha apresentado maior índice de desfolha, seus valores são próximos dos alcançados por Souza et al. (2006) na colheita manual do café, de $167,4 \mathrm{~g} \mathrm{~kg}^{-1}$, e na colheita mecânica com derriçadora, de $120,3 \mathrm{~g} \mathrm{~kg}^{-1}$.

Não houve diferença significativa entre os dados de carga pendente colhidos no segundo experimento, com valor médio de 4,37 L por planta (Tabela 3).

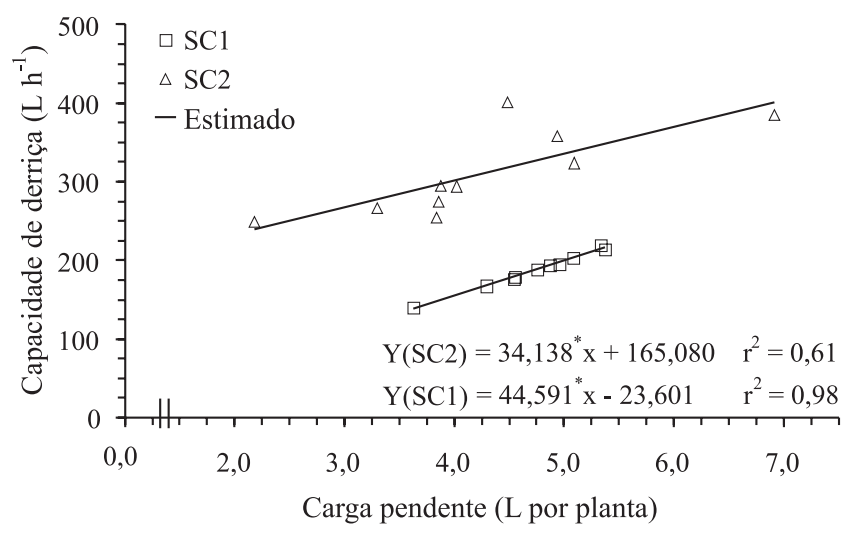

Figura 1. Capacidade de derriça em função da carga pendente do cafeeiro, para os respectivos sistemas de colheita. *Significativo a $5 \%$ de probabilidade, pelo teste $\mathrm{t}$.

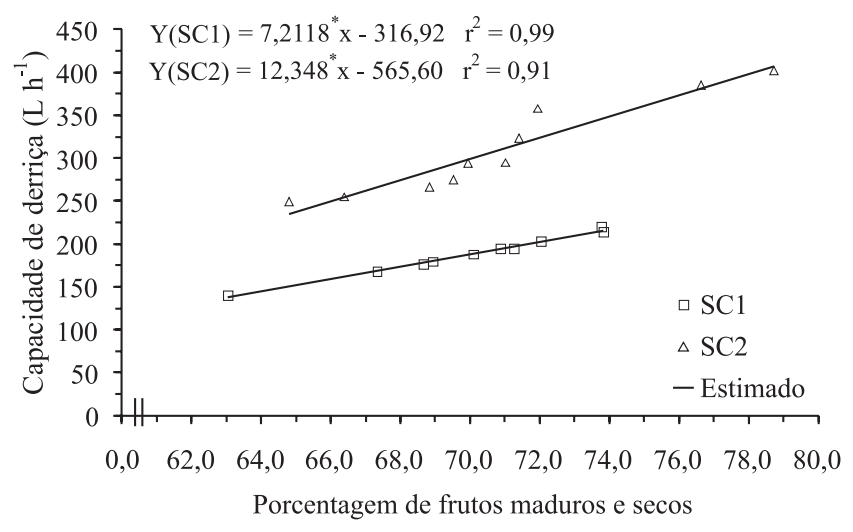

Figura 2. Capacidade de derriça em função da porcentagem de frutos maduros e secos, para os respectivos sistemas de colheita. *Significativo a 5\% de probabilidade, pelo teste t.
A porcentagem de frutos maduros por planta foi superior na lavoura 2, representando uma diferença de aproximadamente 30 pontos porcentuais. Quando as derriçadoras portáteis trabalharam na lavoura 2 , com 91,3\% de frutos maduros, observou-se maior capacidade de derriça e índice de desfolha e menor porcentagem de verdes nos frutos derriçados e quantidade de frutos não derriçados (Tabela 3).

A porcentagem de frutos verdes derriçados foi superior à obtida por Oliveros-Tascón et al. (2005), de 10,5\%. Desse modo estudos devem ser desenvolvidos sobre os parâmetros que caracterizam a vibração causada pelas máquinas ao cafeeiro, a fim de melhorar a capacidade de seletividade de frutos maduros.

O nível de ruído de fundo, verificado durante os testes, foi de 47,2 dBA. Os níveis de ruído emitido pela derriçadora portátil foram semelhantes nas duas lavouras de café (Tabela 3 ). Todos os valores de níveis de ruído emitidos pelas máquinas, independentemente das características da lavoura, estiveram acima dos limites de conforto, estabelecidos pela Norma NBR 10152, que corresponde a uma exposição de 85 dBA durante uma jornada de trabalho de 8 horas. Resultados semelhantes foram registrados por Souza et al. (2005).

Como a carga pendente foi semelhante entre as lavouras, o melhor desempenho das derriçadoras portáteis obtido na lavoura 2 está relacionado com a maior porcentagem de frutos maduros. Resultado semelhante foi obtido por Souza et al. (2002), que verificaram que os frutos maduros são mais fáceis de serem derriçados que os frutos verdes, o que explica a maior capacidade de derriça e menor quantidade de frutos verdes presentes nos frutos colhidos e dos frutos não derriçados, que ficaram no cafeeiro, verificada na colheita da lavoura 2 .

$\mathrm{Na}$ comparação dos resultados obtidos durante a derriça total e seletiva dos frutos do cafeeiro, observouse redução de $38 \%$ no índice de desfolha, e aumento de $56,8 \%$ na capacidade de derriça, quando foi utilizada a operação seletiva. Esse fato está relacionado com a maior

Tabela 3. Carga pendente (litros por planta), frutos maduros por planta (\%), capacidade de derriça (L h-1), índice de desfolha ( $\left.\mathrm{g} \mathrm{L}^{-1}\right)$, nível de ruído (dBA), frutos não derriçados (litros por planta) e frutos verdes derriçados $(\%)^{(1)}$.

\begin{tabular}{|c|c|c|c|c|c|c|c|}
\hline Lavoura & $\begin{array}{c}\text { Carga } \\
\text { pendente }\end{array}$ & $\begin{array}{c}\text { Frutos } \\
\text { maduros }\end{array}$ & $\begin{array}{c}\text { Capacidade de } \\
\text { derriça }\end{array}$ & $\begin{array}{l}\text { Índice de } \\
\text { desfolha }\end{array}$ & $\begin{array}{c}\text { Nível } \\
\text { de ruído }\end{array}$ & $\begin{array}{c}\text { Frutos verdes } \\
\text { derriçados }\end{array}$ & $\begin{array}{l}\text { Frutos não } \\
\text { derriçados }\end{array}$ \\
\hline 1 & $4,34 a$ & $61,6 a$ & $452,4 a$ & $82,12 \mathrm{a}$ & $94,8 \mathrm{a}$ & $34,3 \mathrm{a}$ & $1,9 \mathrm{a}$ \\
\hline 2 & $4,40 \mathrm{a}$ & $91,3 b$ & $520,5 b$ & $108,30 \mathrm{~b}$ & $96,1 \mathrm{a}$ & $17,0 \mathrm{~b}$ & $0,6 \mathrm{~b}$ \\
\hline
\end{tabular}

(1)Médias seguidas de mesma letra, nas colunas, não diferem entre si pelo teste $\mathrm{F}$, a $1 \%$ de probabilidade. 
porcentagem de frutos maduros e o menor estádio de desenvolvimento das plantas, observadas nas lavouras onde foi realizada a operação da derriça seletiva. Resposta semelhante da capacidade de derriça de acordo com o estádio de desenvolvimento do cafeeiro, foi obtida por Souza (2004), que verificou que, quanto maior é o estádio de desenvolvimento, maior é o número de galhos e a altura da planta, dificultando o processo de colheita.

\section{Conclusões}

1. O sistema de colheita que utiliza duas derriçadoras portáteis simultaneamente na mesma linha de plantio apresenta melhor desempenho operacional.

2. A capacidade de derriça aumenta com o incremento da carga pendente e da porcentagem de frutos maduros.

3. A colheita seletiva é influenciada pela porcentagem de frutos maduros do cafeeiro.

4. Os níveis de ruído emitidos pelas derriçadoras são maiores que os limites de conforto estabelecidos pela Norma NBR 10152, exigindo-se uso de protetor auricular durante sua operação.

\section{Agradecimentos}

Ao Programa Nacional de Pesquisa e Desenvolvimento do Café (PNP\&D Café) e ao CNPq, pelo suporte financeiro; ao CNPq e à Capes, pelas bolsas de estudo e de pesquisa.

\section{Referências}

ABNT. Norma NBR 10152 (NB 95): níveis de ruído para conforto acústico. Rio de Janeiro, 1987. 4p.
ARISTIZÁBAL-TORRES, I.D.; OLIVEROS-TASCÓN, C.E.; SANZ-URIBE, J.R.; MONTOYA-RESTREPO, E.C.; ALVAREZMEJÍA, F. Cosecha mecánica de café aplicando vibraciones circulares al tallo del cafeto. Cenicafé, v.51, p.41-53, 2000.

BARBOSA, J.A.; SALVADOR, N.; SILVA, F.M. Desempenho operacional de derriçadores mecânicos portáteis, em diferentes condições de lavouras cafeeiras. Revista Brasileira de Engenharia Agrícola e Ambiental, v.9, p.129-132, 2005.

BÁRTHOLO, G.F.; GUIMARÃES, P.T.G. Cuidados na colheita e preparo do café. Informe Agropecuário, v.18, p.33-42, 1997.

BRASIL. Consolidação das leis do trabalho. 23.ed. São Paulo: Saraiva, 1998. 936p.

FILGUEIRAS, W.H. Modelagem da planta de café por elementos finitos para estudo de colheita por vibração. 2000. 81p. Dissertação (Mestrado) - Universidade Federal de Viçosa, Viçosa.

MATIELLO, J.B.; SANTINATO, R.; GARCIA, A.W.R.; ALMEIDA, S.R.; FERNADES, D.R. Cultura de café no Brasil: novo manual de recomendações. Rio de Janeiro: MAPA/PROCAFÉ, 2002. 387p.

OLIVEROS-TASCÓN, C.E.; BENÍTEZ-MORA, R.; ÁLVAREZMEJÍA, F.; ARISTIZÁBAL-TÓRRES, I.D.; RAMÍREZ-GÓMEZ, C.A.; SANZ-URIBE, J.R. Cosecha del café con vibradores portátiles del tallo. Revista Facultad Nacional de Agronomía, v.58, p.26972708, 2005.

RIBEIRO JÚNIOR, J.I. Análises estatísticas no SAEG. Viçosa: UFV, 2001. 301p.

SILVA, F.M.; CARVALHO, G.R.; SALVADOR, N. Mecanização da colheita do café. Informe Agropecuário, v.18, p.43-54, 1997.

SOUZA, C.M.A. de. Desenvolvimento e modelagem de sistemas de derriça e de abanação de frutos do cafeeiro. 2004. 123p. Tese (Doutorado) - Universidade Federal de Viçosa, Viçosa.

SOUZA, C.M.A. de; QUEIROZ, D.M. de; PINTO, F. de A. de C.; CORRÊA, P.C. Derriça de frutos de café por vibração. Revista Brasileira de Armazenamento, v.27, p.32-37, 2002.

SOUZA, C.M.A. de; QUEIROZ, D.M. de; PINTO, F. de A. de C.; TEIXEIRA, M.M. Desempenho de derriçadora portátil de frutos do cafeeiro. Engenharia Agrícola, v.25, p.791-800, 2005.

SOUZA, C.M.A. de; QUEIROZ, D.M. de; RAFULL, L.Z.L.; CECON, P.R. Comparação entre derriça manual e mecânica de frutos de cafeeiro. Revista Ceres, v.53, p.36-40, 2006. 